\title{
Thermal Degradation of HDPE Short Fibers Reinforced Epoxy Composites
}

\author{
T. Niranjana Prabhu ${ }^{1}$, T. Demappa ${ }^{2}$, V. Harish ${ }^{3}$ \\ ${ }^{1}$ Department of Chemistry, East Point College of Engineering for Women, Bangalore - 560049, INDIA \\ ${ }^{2}$ Departments of Studies in Polymer Science, University of Mysore, Sir M. Visvesvaraya Post Graduate Centre, \\ Tubinkere, Mandya - 571402, INDIA \\ ${ }^{3}$ Department of Physics, GovernmentFirst Grade College, Shimoga - 577201, INDIA
}

\begin{abstract}
Thermogravimetric analysis was carried out to investigate the thermal degradation of High Density Poly Ethylene (HDPE) short fibers reinforced epoxy composites. Three composites with 5, 10 and $15 \%$ by weight of HDPE short fiber composition were prepared using epoxy as matrix material. The HDPE short fiber used as reinforcing material into the resin helps in retarding the thermal degradation of epoxy. It has been noted that there is a composition dependence on the course of kinetic slower of epoxy with fiber loading. Of three compositions, the $10 \%$ HDPE filled Epoxy composite shows better thermal resistance. This has been understood from the derivative peak temperatures $365^{\circ} \mathrm{C}$ and $391^{\circ} \mathrm{C}$ corresponding to $5 \%$ and $10 \%$ levels of fiber loading respectively. Similarly the weight retention at IDT for neat epoxy, 5\% and $10 \%$ fiber levels in epoxy were 83\%, 84\% and 87\% respectively. The $15 \%$ HDPE filled Epoxy composite shows downward trend with respect to derivative peak temperature and weight retention at IDT. The Horowitz-Metzger method was used to calculate the activation energies and results are tabulated. Morphological analysis was carried out with scanning electron microscopy (SEM) to evaluate the dispersion of the fibers in the epoxy matrix. UL-94 Horizontal and Vertical Burning tests conducted for the samples indicated that these materials can be used in structural, agricultural and decorative applications.
\end{abstract}

Key Words: Composites; HDPE fiber; Epoxy resin; Thermogravimetric analysis; Activation Energy

\section{Introduction:}

HDPE is well known as low cost matrix system in the preparation of composites that are made by the incorporation of fillers like glass ${ }^{1}$ and metal ${ }^{2}$. Also modified HDPE is used as matrix system in the preparation of composite materials ${ }^{3,4}$. Epoxy resins have been extensively used in many industrial applications such as coatings, adhesives, composites, laminates because of their low cost, good chemical and electrical resistance, superior mechanical properties and low shrinkage upon curing and outstanding adhesion properties ${ }^{5,6,7}$. The short fiber reinforcements into polymer matrix bring about the improved impact strength and fracture toughness ${ }^{8}$. H. Kaddami et al have used short palm tree fibers as reinforcing materials into epoxy and unsaturated polyester and have shown epoxy is bonding well with fibers than unsaturated polyester ${ }^{9}$. Since there is always thermal and mechanical stress during fabrication process and utilization, it is important to know the effects of processing temperature associated with the processing duration. Fundamental information regarding the thermal behavior of the composite materials is obtained from Thermogravimetric analysis (TGA) and Differential scanning calorimetric (DSC) analysis ${ }^{10}$. The literature available suggests that HDPE (thermoplastic) is used as matrix system with different fillers ${ }^{1,2}$. Less attention has been paid on HDPE fibers as filler material. But the incorporation of polypropylene fibers as filler into epoxy matrix is reported in our earlier studies ${ }^{11}$. Composite materials involving thermoplastics as fillers (utilization of waste HDPE fibers) and thermosets as matrix are produced and in this study, the thermal degradation kinetics of these materials was evaluated using TGA technique.

\section{EXPERIMENTAL:}

The matrix system consisted of a diglycidyl ether of bisphenol - A epoxy resin (LY 556) and a room temperature curing hardener with a tetramine functional group (HY951), were supplied by Ciba Giegy Ltd. (Bombay, INDIA). The density of the neat resin was found to be $1.17 \mathrm{~g} / \mathrm{cc}$. The HDPE fibers were obtained from Reliance Polymers, Ltd. (Bombay, INDIA). These HDPE fibers were cut into short fiber with an average length of $3 \mathrm{~mm}$ and the average diameter of the fibers was $130 \mu \mathrm{m}$.

\section{Preparation of the Composites:}

A measured quantity of epoxy resin was mixed with a pre-weighed amount of HDPE fiber and the hardener was then added to this mixture with gentle stirring in order to minimize the formation of air bubbles. The specimen preparation was made in a Teflon mold of size, $100 \mathrm{~mm}$ diameter $\times 3 \mathrm{~mm}$ thickness with a coating 
of silicone releasing agent for easy removal of cast specimen. The mixture was left to cure at room temperature for about $48 \mathrm{~h}$. The cured rigid plate sample was withdrawn from the mold and post cured at $80^{\circ} \mathrm{C}$ for $4 \mathrm{~h}$. Similarly the epoxy based composite samples with 5, 10, and $15 \mathrm{wt} \%$ of short HDPE fibers were cast and a neat epoxy sample was prepared by mixing the resin and hardener with same curing conditions.

\section{TGA and Morphological analysis:}

TGA measurements were carried out with $10 \mathrm{mg}$ of HDPE fiber - epoxy resin composite samples at a heating rate of $10^{\circ} \mathrm{C} / \mathrm{min}$ in a nitrogen atmosphere with a Thermogravimetric Analyzer (SDTQ 600, TA Instruments, USA). The thermal decomposition of each sample occurred in a programmed temperature range between room temperature and $800^{\circ} \mathrm{C}$. The continuous records of the weight loss and temperature were determined and analyzed to determine the nature of the thermal degradation, initial degradation temperature, and complete degradation temperature. The morphology of the prepared composites was examined with a LEICA S440i Scanning Electron Microscope (Leica Cambridge Ltd., UK).

UL-94 Horizontal and Vertical Burning Tests: The UL-94 Horizontal Burning test was conducted for samples of thickness $3 \mathrm{~mm}, 127 \mathrm{~mm}$ (5.0 inches) long and $12.7 \mathrm{~mm}(0.5$ inches) wide in a horizontal position over a standard Bunsen burner. The test measures burn rate in $\mathrm{mm} / \mathrm{min}$ or inches/min. For the same sized samples UL94 Vertical Burning test was also conducted. Both tests were carried as per the procedure of Underwriters Laboratories $^{12}$.

\section{Results And Discussion:}

The weight loss usually indicates the rate of polymer decomposition and often gives degradation mechanisms and other important information related to physical and chemical changes in various environmental conditions ${ }^{13}$.

Weight loss of the composites as a function of temperature was determined by TGA technique and is an irreversible process due to thermal degradation. Thermograms of 5, 10 and $15 \%$ HDPE short fiber - epoxy resin composites show a two-stage weight loss; however the thermogram of neat epoxy and HDPE fiber alone shows single stage degradation (Figure1).

The neat epoxy resin shows the single stage degradation in the temperature range between $335^{\circ} \mathrm{C}$ and $426^{\circ} \mathrm{C}$. Derivative peak temperature $\left(\mathrm{T}_{\max }\right)$ was found to be at $362^{\circ} \mathrm{C}$. Also the HDPE fiber shows single stage degradation in the temperature range between $413^{\circ} \mathrm{C}$ and $485^{\circ} \mathrm{C}$ with $\mathrm{T}_{\max }$ at $469^{\circ} \mathrm{C}$.

The $5 \%$ HDPE short fiber - epoxy resin composite system shows the major thermal degradation in the temperature range between $339^{\circ} \mathrm{C}$ and $392^{\circ} \mathrm{C}$. It was clearly confirmed by the derivative weight loss curve exhibiting a peak at $365^{\circ} \mathrm{C}\left(\mathrm{T}_{\max 1}\right)$. The degradation in this range may be due to partial resin decomposition. The filler material retards the weight loss of the polymer. However the second stage degradation occurring in the higher temperature range between $489^{\circ} \mathrm{C}$ and $540^{\circ} \mathrm{C}$ may be attributed to the fact that of improved filler-resin bonding. This was confirmed by the derivative weight loss curve exhibiting a peak at $510^{\circ} \mathrm{C}\left(\mathrm{T}_{\max 2}\right)$. The complete decomposition was observed at around $600^{\circ} \mathrm{C}$.

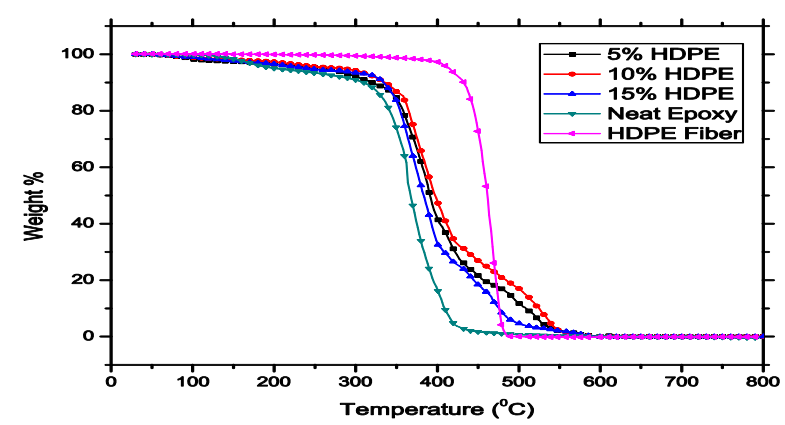

Figure 1. Thermograms of neat epoxy, HDPE fibers and epoxy resin reinforced with HDPE short fibers.

The $10 \%$ HDPE fiber - epoxy resin composite system shows the major thermal degradation in the temperature range between $353^{\circ} \mathrm{C}$ and $420^{\circ} \mathrm{C}$, and $\mathrm{T}_{\max 1}$ was found to be at $371^{\circ} \mathrm{C}$. However the second stage degradation occurred in the temperature range between $503^{\circ} \mathrm{C}$ and $548^{\circ} \mathrm{C}$ with $\mathrm{T}_{\max 2}$ at $522^{\circ} \mathrm{C}$. This may be attributed to the fact that of increased filler fraction and improved filler-resin bonding. The complete decomposition has occurred at around $590^{\circ} \mathrm{C}$.

The $15 \%$ HDPE fiber - epoxy resin composite system shows the thermal degradation in the temperature range between $350^{\circ} \mathrm{C}$ and $412^{\circ} \mathrm{C}$. The $\mathrm{T}_{\max 1}$ in this range was at $369^{\circ} \mathrm{C}$. The second stage 
degradation occurred in the temperature range between $453^{\circ} \mathrm{C}$ and $482^{\circ} \mathrm{C}$ with $\mathrm{T}_{\max 2}$ at $470^{\circ} \mathrm{C}$. The complete degradation has occurred at the temperature around $595^{\circ} \mathrm{C}$.

The thermal resistance for the composites prepared is increasing in both first and second stage degradation with the increase in HDPE fiber content to certain extent and then decreasing after the critical level of the fiber content. The neat epoxy shows $83 \%$ weight retention, $5 \%$ HDPE fiber - epoxy resin composite system shows the $84 \%$ weight retention, $10 \%$ HDPE fiber - epoxy resin composite system shows the $87 \%$ weight retention and $15 \%$ HDPE fiber - epoxy resin composite system shows $82 \%$ weight retention at initial degradation temperature, IDT.

The results show that HDPE short fibers used as reinforcing materials retard the first stage thermal degradation, and this can be attributed to the binding of the fibers to the resin. An increase in the weight percentage of the fiber material increases the thermal resistance and thermal stability to a certain extent. This may be due to the increased binding of fibers to the resin. Of the three composites, the $10 \%$ HDPE fiber epoxy resin composite shows very good thermal resistance, which has been shown by the increase in $\mathrm{T}_{\max }$ from $365^{\circ} \mathrm{C}$ for the $5 \% \mathrm{HDPE}$ fiber - epoxy resin composite to $371^{\circ} \mathrm{C}$ for the $10 \% \mathrm{HDPE}$ fiber - epoxy resin composite. Also the thermal stability for $10 \%$ HDPE fiber - epoxy resin composite is more when compared to other samples, which has been shown by higher weight retention of $87 \%$ at IDT (Table 1). However, there is a marginal decrease in the $\mathrm{T}_{\max }$ i.e. $369^{\circ} \mathrm{C}$ and weight retention at IDT for the $15 \%$ HDPE fiber - epoxy resin composite i.e. $82 \%$. Because increasing the volume fraction of filler beyond certain limit reduces the performance of the composite, as an optimum amount of the matrix is necessary for the composite system ${ }^{11}$. An increase of the HDPE short fiber after critical level may not cause the increase in temperature at maximum rate of decomposition and weight retention at IDT as noted for the $15 \%$ HDPE fiber - epoxy resin composite. For all three composites under study, the major degradation occurs between $339^{\circ} \mathrm{C}$ and $420^{\circ} \mathrm{C}$. The end of degradation for all samples took place around $600^{\circ} \mathrm{C}$.

The Horowitz-Metzger integral kinetic method ${ }^{14}$ was applied to calculate the kinetic parameters. This method helps to determine the degradation activation energy with only one heating rate. In this study, the TGA curves at a heating rate of $10^{\circ} \mathrm{C} / \mathrm{min}$ were used to calculate the degradation kinetics for all samples with the following equation:

$$
\left\lfloor\ln \left\{\ln (1-\alpha)^{-1}\right\}\right\rfloor=\frac{E \theta}{R T_{\text {Max }}^{2}}
$$

Where $\mathrm{E}=$ energy of activation, $\theta=\mathrm{T}-\mathrm{T}_{\mathrm{e}}, \mathrm{T}=$ temperature at time $\mathrm{t}, \mathrm{T}_{\mathrm{e}}=$ temperature at $\mathrm{W} / \mathrm{W}_{0}=1 / \mathrm{e}, \mathrm{W}_{0}=$ Initial weight, $\mathrm{W}=$ Weight at time $\mathrm{t}, \mathrm{R}$ is universal gas constant and $\alpha$ is the heating rate.

The calculated activation energies for neat epoxy, HDPE fiber and for stage 1 and 2 of three composite samples are reported in Table 1 along with other thermal properties such as IDT, weight retention at IDT and derivative peak rate of decomposition $\left(\mathrm{R}_{\max }\right)$.

Table 1. Thermal Properties of the HDPE-EPOXY composites

\begin{tabular}{|c|c|c|c|c|c|c|c|c|c|c|}
\hline & \multicolumn{4}{|c|}{ I Stage Degradation } & \multicolumn{4}{|c|}{ II Stage Degradation } \\
\cline { 2 - 12 } Samples & $\begin{array}{c}\text { IDT1 } \\
\left({ }^{\circ} \mathrm{C}\right)\end{array}$ & $\begin{array}{c}\text { Weight } \\
\text { Retention } \\
\text { at IDT } \\
(\%)\end{array}$ & $\begin{array}{c}\mathrm{T}_{\max 1} \\
\left({ }^{\circ} \mathrm{C}\right)\end{array}$ & $\begin{array}{c}\mathrm{R}_{\max 1} \\
(\mathrm{wt} \% / \mathrm{min})\end{array}$ & $\begin{array}{c}\text { Activation } \\
\text { Energy } \\
(\mathrm{E} 1), \\
\mathrm{KJ} / \mathrm{mol}\end{array}$ & $\begin{array}{c}\mathrm{T}_{1 / 2} \\
\left({ }^{\circ} \mathrm{C}\right)\end{array}$ & $\begin{array}{c}\mathrm{IDT} 2 \\
\left({ }^{\circ} \mathrm{C}\right)\end{array}$ & $\begin{array}{c}\mathrm{T}_{\max 2} \\
\left({ }^{\circ} \mathrm{C}\right)\end{array}$ & $\begin{array}{c}\mathrm{R}_{\max 2} \\
(\mathrm{wt} \% / \mathrm{min})\end{array}$ & $\begin{array}{c}\text { Activation } \\
\text { Energy } \\
(\mathrm{E} 2), \\
\mathrm{KJ} / \mathrm{mol}\end{array}$ \\
\hline $\begin{array}{c}\text { Neat } \\
\text { Epoxy }\end{array}$ & 335 & 83 & 362 & 1.215 & 7.87 & 371 & - & - & - & - \\
\hline $\begin{array}{c}\text { HDPE } \\
\text { fiber }\end{array}$ & 413 & 95 & 469 & 1.95 & 14.26 & 460 & - & - & - & - \\
\hline $\begin{array}{c}5 \mathrm{HDPE}- \\
\text { EP }\end{array}$ & 339 & 84 & 365 & 0.71 & 9.41 & 374 & 489 & 510 & 0.252 & 86.92 \\
\hline $\begin{array}{c}\text { 10HDPE- } \\
\text { EP }\end{array}$ & 353 & 87 & 371 & 1.035 & 11.12 & 401 & 503 & 522 & 0.312 & 87.12 \\
\hline $\begin{array}{c}\text { 15HDPE- } \\
\text { EP }\end{array}$ & 350 & 82 & 369 & 1.10 & 10.21 & 398 & 453 & 470 & 0.361 & 69.22 \\
\hline
\end{tabular}

The results obtained show that the activation energy increases with increasing fiber content to certain extent in both stages and suggests $10 \%$ HDPE fiber - epoxy resin composite system possess the better thermal resistance and thermal stability. The activation energy calculated for both stage of degradation using the slopes obtained from plot of $\left\lfloor\ln \left\{\ln (1-\alpha)^{-1}\right\}\right\rfloor$ vs $\theta$ (figure 2 and 3) shows the increase with increase in fiber content to a certain extent in both stages of degradation. This is attributed to the fact that the addition of fibers influences the degradation behavior of the epoxy resin by self-decomposition at relatively low temperatures and 
then forms protective layers and releases noncombustible gases at higher temperatures to increase the thermal resistance. Further, the weight retention at IDT data (Table 1) shows the good thermal stability for $10 \mathrm{wt} \%$ HDPE short fiber - epoxy resin composite system with $87 \%$ weight retention at IDT which is more than other composite samples and neat epoxy. Considering the thermal degradation parameters observed in both degradation stages for these samples, it is understood that $10 \%$ HDPE sample has a better thermal resistance and thermal stability. In general the thermal stability of all samples is in the order of $10 \%>15 \%>5 \%>0 \%$ HDPE composition. This study has revealed that there is a critical composition level beyond which the thermal resistance and thermal stability of epoxy filled with HDPE fibers does not increase.

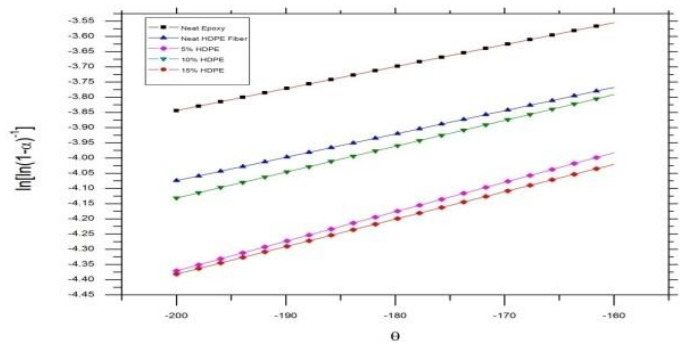

Figure 2. Plots of $\ln \left[\ln (1-\alpha)^{-1}\right]$ versus $\theta$ for calculating the activation energies of stage I of the decomposition for all samples by the Horowitz-Metzger method.

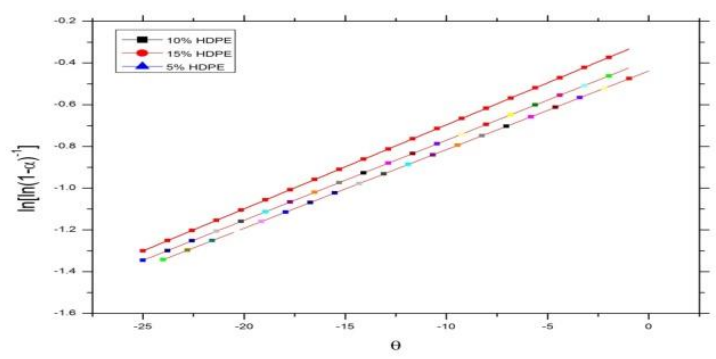

Figure 3. Plots of $\ln \left[\ln (1-\alpha)^{-1}\right]$ versus $\theta$ for calculating the activation energies of stage II of the decomposition for $5 \%, 10 \%, 15 \%$ HDPE-Epoxy samples by the Horowitz-Metzger method.

Scanning electron microscopy analysis has indicated the good dispersion of the fibers in the matrix which can be seen from figures $4 \mathrm{a}-\mathrm{d}$. The fig $4 \mathrm{a}$ corresponds to the brittle fracture surface of neat epoxy resin. The morphological features of other samples indicate that the introduction of HDPE fibers into Epoxy has reduced the brittleness; however beyond the critical level of fibers there is an increased hardening stress in the fibers as evidenced in micrograph of $15 \mathrm{wt} \%$ HDPE-Epoxy composite sample (fig $4 \mathrm{~h}$.) which may be due to reduced volume fraction of epoxy. Even though there is an increase in thermal parameters with short fiber reinforcement, SEM of all the three composite samples show few holes due to the pulling of the fibers during the breakage of the samples indicating bonding between fibers and matrix is of physical type but not of adhesive type. The lack of wettability of matrix to penetrate the voids on fiber surface might have resulted in fiber pullout $^{15}$. Figures $4 \mathrm{e}-\mathrm{g}$ show the magnified view of cracks along the circumference of the hole formed during the breakage due to pulling of the fiber. The circumferential cracks are observed in the holes of all the samples and the circumferential crack is stronger in the order of $15 \%>10 \%>5 \%$ HDPE. Fiber pull out in all composites have displayed adhesive type bond failure during the impact and crack length is increased with the increase in the fiber content.
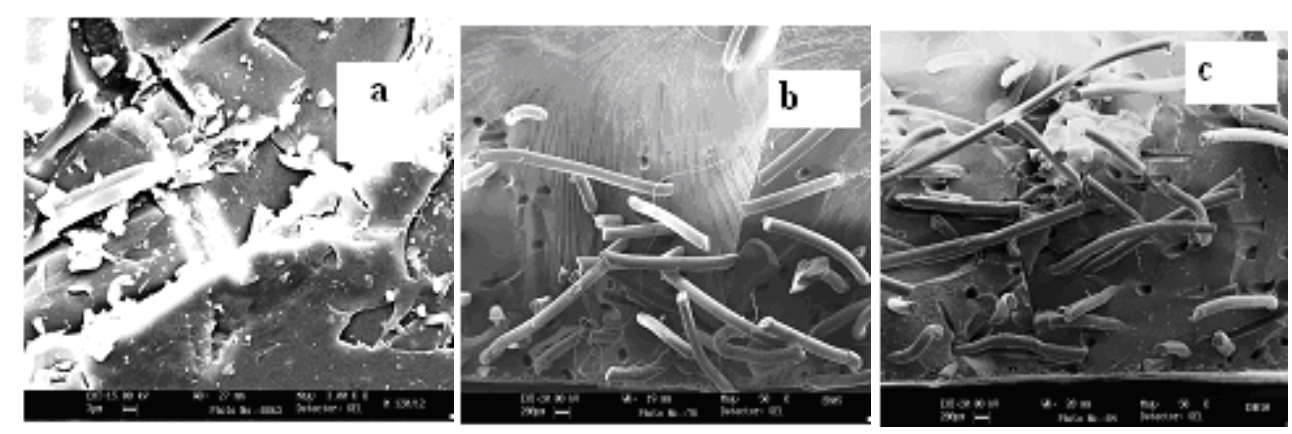

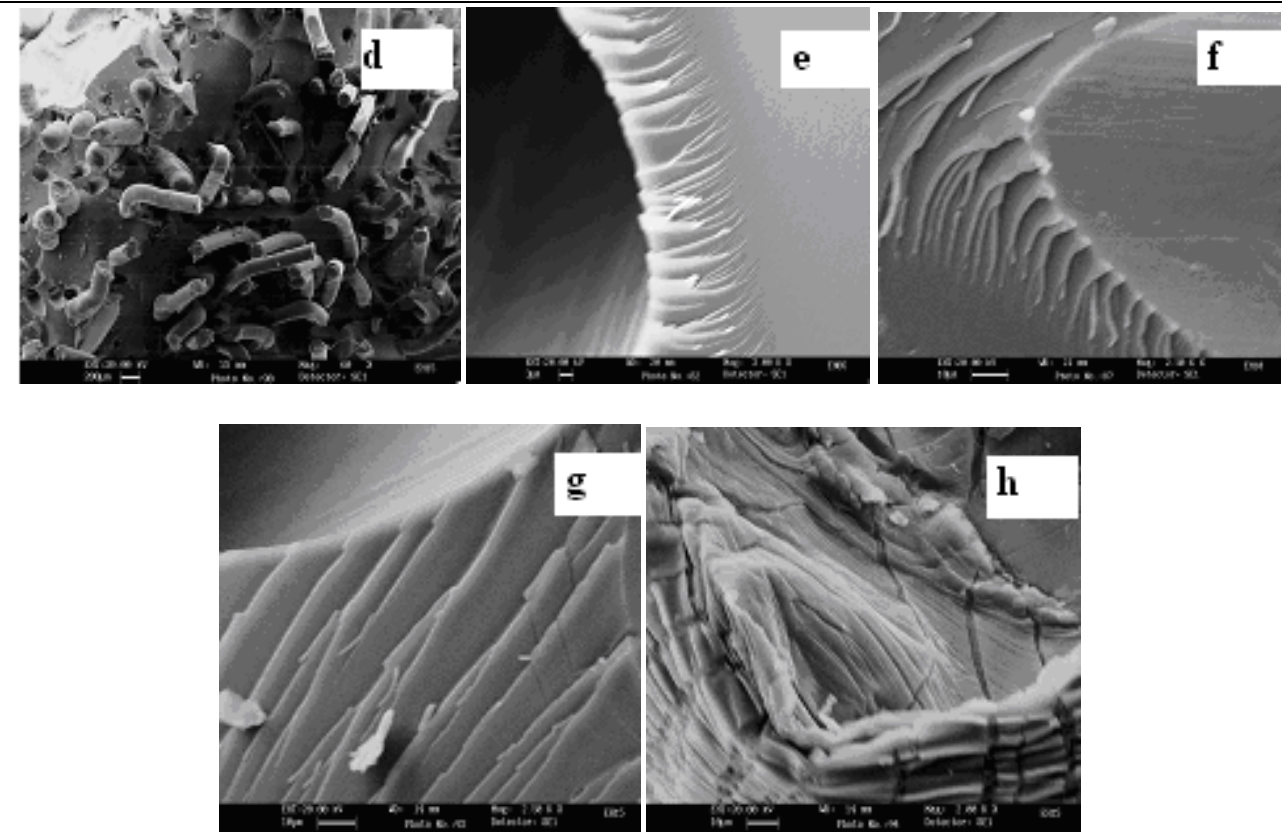

Fig. 4. SEM of fractured surface of a) Neat Epoxy, b) 5\% HDPE-Epoxy, c) $10 \%$ HDPE-Epoxy, d) $15 \%$ HDPE-Epoxy, e) 5\% HDPE-Epoxy (Magnified view of the Hole), f) $10 \%$ HDPE-Epoxy (Magnified view of the Hole), g) 15\% HDPE-Epoxy (magnified view of the hole) h) 15\% HDPE-Epoxy (magnified view of fiber)

UL-94 Horizontal tests are indicative of materials applications as structural components and UL-94 Vertical tests are indicative of materials usage in electrical and electronic components. UL-94 Horizontal tests for flammability on the samples showed a burning rate $25 \mathrm{~mm} / \mathrm{min}$ for neat sample and $23,21,20 \mathrm{~mm}$ for $5 \%$, $10 \%, 15 \%$ HDPE short fiber reinforcements which are much less than the limiting value of $76 \mathrm{~mm} / \mathrm{min}$. The materials burned with a small bright blue flame and subsequently, with a bright yellow flame, which continued to burn after removal of the ignition source. The reduction in burning rate may be due to improved interfacial bonding between matrix and fiber. However UL-94 Vertical Burning tests for these samples showed burning over $30 \mathrm{sec}$ after the removal of flame with dripping which ignited the cotton kept $300 \mathrm{~mm}$ below the sample. The materials failed for V0, V1 and V2 tests. These test results indicated that the composites can be used for structural, agricultural and decorative applications.

\section{Conclusions:}

An increase in the fiber content increases the thermal resistance and thermal stability of composites to a certain extent. Fibers can be added until the critical level to get thermally stable composites. The $10 \%$ HDPE fiber - epoxy resin composite gives better thermal resistance and thermal stability because the $15 \%$ HDPE fiber - epoxy resin composite's thermal resistance and thermal stability is marginally decreased with an increase in the weight percentage of the fiber material. The activation energy in both degradation stages increases with an increase in the fiber content to a certain extent. This is attributed to the fact that the addition of fibers influences the degradation behavior of the epoxy resin by self-decomposition at relatively low temperatures and then forms protective layers and releases noncombustible gases at higher temperatures. Marginal increase in thermal stability is further confirmed by higher weight retention at IDT for $10 \%$ HDPE fiber - epoxy resin composite $(87 \%)$ compared to neat epoxy (83\%), $5 \%(84 \%)$ and $15 \%$ HDPE fiber - epoxy resin composite (82\%) samples.

Scanning electron microscopy analysis has indicated the good dispersion of the fibers in the matrix. The morphological features indicate that the introduction of HDPE fibers into Epoxy has reduced the brittleness, however beyond the optimum fraction there is an increased stress in the fibers as evidenced in micrograph of 15 $\%$ HDPE-Epoxy composite sample. Also the samples have shown physical type of binding that has led to some fiber pullout.

UL-94 Horizontal burning tests conducted on the composite samples have showed burning rate less than the limiting value; however for UL-94 Vertical burning tests, the materials have burned over $30 \mathrm{sec}$ with dripping, igniting the cotton beneath the sample. These test results indicated that the composites can be used for structural, agricultural and decorative purposes. 


\section{References:}

[1] Muhammed S. Hameed, Faiz A. Jamil, Firas A. Stephan, "Thermal stability of glass-filled polyethylenes", Thermochimica acta, 246, 167-174, 1994.

[2] W. Bare, C. Albano, J. Reyes, N. Dominguez, "Effect of irradiation on the mechanical properties of high-density polyethylene reinforced with metallic fibers", Surface and Coatings Tech., 158-159, 404-407, 2002.

[3] A. Pegoretti, M. Ashkar, C. Migliaresi, G. Marom, "Relaxation processes in polyethylene fiber-reinforced polyethylene composites" Comp. Sci. Tech., 60, $1181-1189,2000$.

[4] Xingmin Zhuang, Xiong Yan, "Investigation of damage mechanisms in self-reinforced polyethylene composites by acoustic emission” Comp. Sci. Tech., 66, 444 - 449, 2006.

[5] Adomenas A, Curran K, and Falconer-Flint M, "Surface Coatings", $3^{\text {rd }}$ Ed. Vol.1, New South Wales University Press, 1993.

[6] Bucknall, CB, "Toughened Plastics". Applied Science Publishers, London, 1990.

[7] Chinnakkannu Karikal Chozhan, Muthukaruppan Alagar, Rajkumar Josephine Sharmila, Periyannan Gnanasundaram, "Thermo mechanical behaviour of unsaturated polyester toughened epoxy-clay hybrid nanocomposites”, J. Polym. Res., 14, 319-328, 2007.

[8] Renee M. Bagwell, Robert C. Wehterhold, "Fiber pullout behavior and impact toughness of short shaped copper fibers in thermoset matrices" Composites: Part A, 36, 683-690, 2005

[9] Hamid Kaddami, Alain Dufresne, Bertine Khelifi, Abdelkader Bendahou, Moha Taourirte, Mustapha Raihane, Nathalie Issartel, Henry Sautereau, Jean-Franc, ois Ge'rard, Noureddine Sami, "Short palm tree fibers - Thermoset matrices and composites" Composites: Part A, 37, 1413-1422, 2006.

[10] Wielage b, Lampke T, Mark G, Nestler K, Starke D., "Thermogravimetric and differential scanning calorimetric analysis of natural fibers and polypropylene" Thermochim. Acta., 337, 169-77, 1999

[11] T. Niranjana Prabhu, Y. J. Hemalatha, V. Harish, K. Prashantha, P. Iyengar, "Thermal degradation of Epoxy Resin Reinforced with Polypropylene Fibers", J. of Appl. Polym. Sci., 104, 500-503, 2007

[12] UL-94 tests for flammability of plastic materials, Underwriters Laboratories, Northbrook, 1982.

[13] Sung-Bok Kwak and Jae - Do Num, Polym. Sci. and Engg, 42, 8, 1674 - 1685., 2002

[14] Horowitz, H. H.; Metzger, G. "A new analysis of thermogravimetric data", Anal Chem, 35, 1464, 1963

[15] Krishnan K. Chawla, Composite Materials: Science and Engineering, $2^{\text {nd }}$ Edition, Springer, 1998. 